\title{
Hurricane Irene and Tropical Storm Lee: How Unusual Were They in the Catskill Mountains?
}

\author{
Allan Frei* and Petra Kelly-Voicu \\ Department of Geography, \\ Program in Environmental Studies, Hunter College, \\ CUNY Institute for Sustainable Cities, New York, USA
}

Published 13 December 2017

\begin{abstract}
During the late summer and early autumn of 2011, the Catskill Mountains in south-central New York State experienced devastating flooding associated with former Hurricane Irene and former Tropical Storm Lee. Even in this particularly flood-prone region, the events of fall 2011 are perceived to be unique in the known history of the region and marked a turning point in the perceptions of residents about climate change. Here, precipitation and stream gage records are analyzed to determine just how unusual this season was. The historical precipitation gage record requires careful analysis due to the changing availability of stations. After a set of stations is developed that is appropriate for this analysis, events of lengths 1 day, 5 days, and 60 days are analyzed to identify regionally significant events (as opposed to events localized to one basin) since the early 20th century and to evaluate Irene and Lee in that historical context. Gage record results corroborate the perceptions of local residents that the period between 1996 and 2011, and in particular the events of fall 2011, were unprecedented in the last 100 years and as inferred from analyses of regional tree rings, probably in the last 500 years.
\end{abstract}

Keywords: Storms; floods; Hurricane Irene; Tropical Storm Lee; Catskill Mountains; New York State; water supply.

\section{Introduction}

The fall season of 2011 was momentous for residents of the Catskill Mountains in south-central New York State in the eastern United States. The impacts of (former Hurricane) Tropical Storm Irene on August 28-29, and about a week later

\footnotetext{
*Corresponding author's email: afrei@hunter.cuny.edu

This is an Open Access article published by World Scientific Publishing Company. It is distributed under the terms of the Creative Commons Attribution 4.0 (CC-BY) License. Further distribution of this work is permitted, provided the original work is properly cited.
} 
(former Tropical Storm) Lee on September 5-9, brought tremendous flooding to the region. Catskills rain gages recorded up to $45 \mathrm{~cm}$ of rainfall (Gazoorian 2012; Ralston et al. 2013) during Irene. The flooding by Irene resulted in extensive damage to infrastructure, adding up to over $\$ 1$ billion in damages; roads, homes, and bridges were destroyed, and the storm claimed at least 10 lives (Gazoorian 2012). In fact, Gazoorian (2012) concludes that the maximum daily streamflow from Irene was unique. Lee exacerbated the flooding and runoff as the soils were already saturated (Ralston et al. 2013).

These events marked a turning point in the local perception of extreme events and climate change (Solecki et al. 2014) similar to the impact of Hurricane Sandy, one year later, on New York City and other coastal residents (Miller et al. 2014; Solecki and Rosenzweig 2014). After Irene and Lee, Solecki et al. (2014) interviewed a variety of Catskill stakeholders who, based on their personal experiences, identified emergent (i.e., new or previously unrecognized) vulnerabilities associated with storms and floods, including: the particular vulnerabilities of the transportation, agricultural and tourism sectors of the economy; the unequal impacts on different socioeconomic groups; the weaknesses of physical infrastructure (e.g., road washouts); the advent of flooding in (according to local knowledge) previously un-flooded areas (e.g., in higher elevation areas that were not considered floodplains); and the underestimation of actual flood frequency by quantitative "return periods" provided by experts. These last two perceived vulnerabilities reflect what was anecdotally considered the common perception among watershed residents and experts alike: that the hydrological events of fall 2011, as well as more generally the hydrology of the region during recent years, were unique in the historical record. (Hanlon et al. 2017) found that a variety of stakeholders in the watershed have different priorities for watershed management, but common to all is the issue of flood control. Goebbert et al. (2012) found that beliefs about precipitation changes are more reflective of gage records and associated less with non-climatic factors than beliefs about temperature changes, suggesting that the perceptions of recent hydrological changes in the Catskills are likely to be accurate. Furthermore, there remain in the Catskills a number of residents with family histories in the region, providing a cultural memory that seems to corroborate these perceptions (Brandon et al. 2012).

The main goal of this paper is to evaluate the precipitation and streamflow records from this region to determine whether the instrumental record corroborates the popular perceptions about the exceptionality of recent events. In the following sections, we describe the study region (Section 2); discuss the data (Section 3) and methods (Section 4) employed in this analysis; describe the results (Section 5); and end with a discussion and summary of the main conclusions (Section 6). 


\section{Study Region Climatology and Hydrology}

Our primary study area is the Catskill Mountain region of south-central New York State in the eastern United States. This region has a long and storied history as an area of natural beauty, ecological diversity, and resource extraction (Stradling 2007; Soll 2013). As with many regions located close to large urban areas, Catskill residents have lived in the economic shadow of New York City, and this relationship has shaped the history of the region for at least 200 years (Soll 2013). The role of the city in shaping that history, as well as shaping the physical landscape and hydrology of the region, became overwhelming when the city decided, in the early 1900s, to build reservoirs in the Catskills to serve its municipal water supply and when the city expanded the reservoir system during subsequent decades (Galusha 1999). The 1997 Memorandum of Agreement (along with subsequent addenda) now defines the governance structure of this natural resource and provides a legal framework for a hopefully equitable distribution of resources and shared decision-making in an adaptive management style framework (Soll 2013; Hanlon 2017; Hanlon et al. 2017).

As a result, the six Catskill basins located west of the Hudson River (i.e., West of Hudson (WOH) basins) that provide, on average, 90 percent of the water for approximately nine million consumers in the city and other municipalities, cover most of the Catskill Mountains. (The other 10 percent of the city's water supply is derived from basins east of the Hudson River, which are not discussed further in this analysis.) The New York City Department of Environmental Protection manages this system, which delivers just over one billion gallons per day, most of which remains unfiltered, constituting the largest unfiltered water supply system in the United States.

Figure 1 shows the topography of the region in and around the Catskills, with elevation varying between close to sea level to over $1,000 \mathrm{~m}$. The highest peaks in the region are found on the eastern escarpments of the WOH basins. Surrounding areas have lower mean elevation with less orographic variability. The region is mostly rural and forested with some dairy farms in low-land areas, particularly in the western part of the mountains. About 70 percent $\left(2,850 \mathrm{~km}^{2}\right)$ of the WOH area is part of the New York State Catskill Forest Preserve. Regional hydrology in NYC WOH watersheds is strongly influenced by snowpack and snow melt, particularly during March and April (Matonse et al. 2013).

The three rivers into which these basins naturally drain are also shown on the map. The two westernmost basins, the Cannonsville and Pepacton, release into the west and east branches of the Delaware River which runs down the southwestern side of the region forming the political boundary between New York State and 


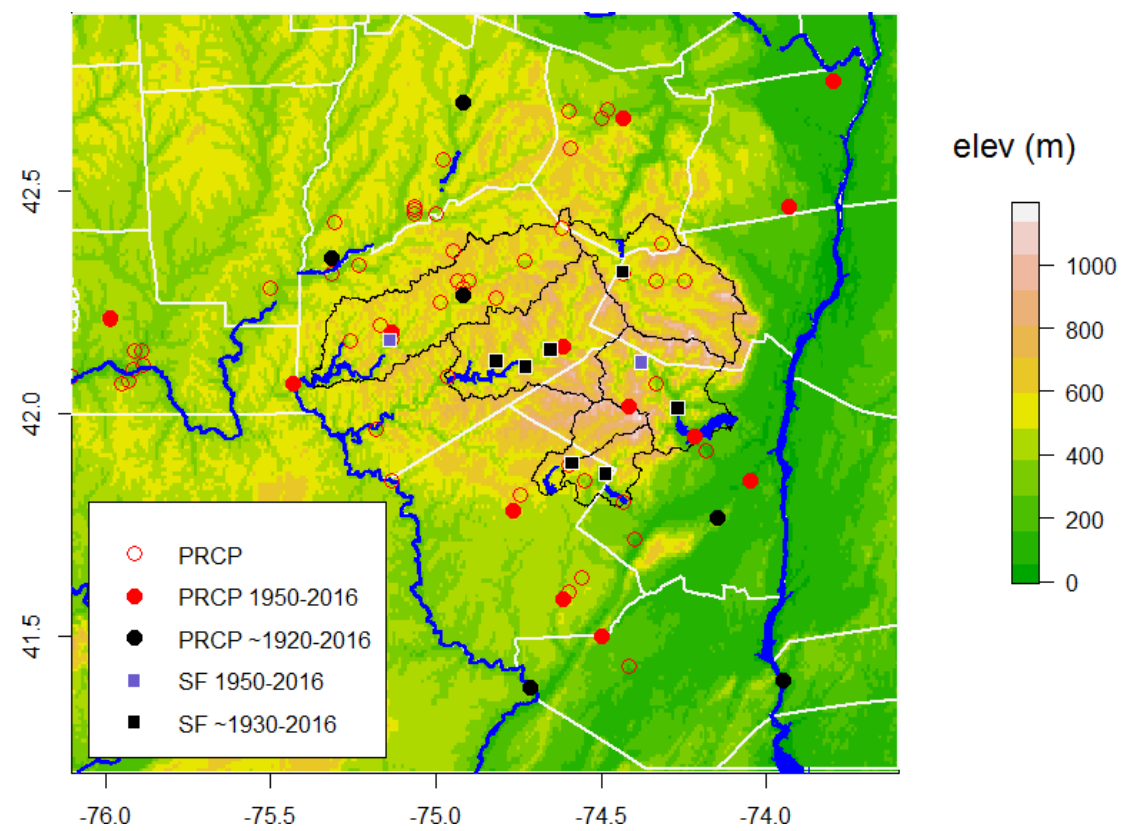

Figure 1. (Color online) Map of Catskill Mountain and Surrounding Region

Notes: The six West of Hudson New York City Water Supply basins are outlined in black. Gage locations for precipitation and streamflow records of various record lengths are shown in circles and squares. Filled symbols represent stations used in the analysis. See text for more details.

Pennsylvania and, farther downstream, between New Jersey and Pennsylvania. The Hudson River, running north-south along the eastern side of the region, naturally drains the three southeastern basins: the Ashokan, Rondout, and Neversink. Finally, a small section of the Mohawk River, a natural tributary of the Hudson into which the northernmost basin - the Schoharie - drains, appears in the northeastern corner of the map. Also, the headwaters of the Susquehanna River are found just east of the Catskills.

Both temperature and precipitation in the Catskills have strong orographic components (Frei et al. 2002; Burns et al. 2007). Historical mean precipitation rates are comparable in all seasons, with annual precipitation between approximately $1,000 \mathrm{~mm}$ and $1,600 \mathrm{~mm}$. Historical daily mean temperatures vary between $-5^{\circ} \mathrm{C}$ and $0^{\circ} \mathrm{C}$ during winter and between $15^{\circ} \mathrm{C}$ and $20^{\circ} \mathrm{C}$ during summer (Matonse and Frei 2013). The combined effects of prevailing storm tracks and orography result in the highest mean and extreme precipitation rates in the southern and eastern basins (Thaler 1996) with the historical contribution of snowfall to total annual precipitation estimated at 20-30 percent depending on the period of record (Frei et al. 2002; Anandhi et al. 2011; Pradhanang et al. 2011). 
Annual maximum precipitation events occur overwhelmingly during late summer and autumn associated with cyclones of tropical origin, sometimes in combination with slowly moving coastal fronts, as well as with mid latitude systems (Matonse and Frei 2013; Acharya et al. 2017; Towey et al. 2017). Annual maximum daily streamflow usually occurs during snow ablation season in late winter and spring, but sometimes occurs during late summer or autumn in association with large precipitation events (Matonse et al. 2013; Matonse and Frei 2013; Towey et al. 2017). The effect of heavy precipitation events on flooding is magnified in regions such as the Catskills due to its mountainous and rocky terrain, which enhances precipitation on windward facing slopes (Thaler 1996; Matonse et al. 2013), minimizes infiltration rate, and maximizes runoff velocity (DeGaetano and Castellano 2013). Flash floods can be spatially localized due to orographically influenced precipitation and variable surface conditions (Teale et al. 2017). Furthermore, the role of antecedent conditions in these events, which can strongly influence the magnitude of the streamflow responses to storms (Lumia et al. 2014; Ivancic and Shaw 2015; Fang and Pomeroy 2016), is important in this region (and will be discussed briefly later in this report).

Analyses of precipitation and stream gage observations across the northeastern United States in general, and in the Catskill Mountains in particular, demonstrate that hydrological variations over the last century or so have not evolved as a simple linear trend toward more extreme conditions, but rather as a series of decadal scale variations with a possible increasing trend superimposed. The period between the mid-1990s and 2012 was active hydrologically (Matonse and Frei 2013; Frei et al. 2015), with the northeast more so than any other region of the United States (Kunkel et al. 2013; Peterson et al. 2013; Melillo et al. 2014). In the Catskills, the magnitude of a 100-year precipitation event in the years 1950-1979 has now become a 60-year event; a 50-year event during the earlier time period has now become a 30-year event (DeGaetano and Castellano 2013). The timing of peak springtime streamflow has been shifting from early April to late March due to earlier snowmelt, with an estimated shift of 5-6 days per 50 years, particularly in the Rondout and Neversink watersheds located on the southeastern escarpment of the Catskills (Burns et al. 2007; Zion et al. 2011). Shulte et al. (2016) find 18- and 26-year periodicities in hydrological activity in this region associated with largescale atmospheric circulation features. Our analysis of extreme events is consistent with those results (discussed subsequently).

Surface water supply systems such as these are particularly vulnerable to extreme flooding events because of the disproportional contribution of large streamflow events to sediment and nutrient loading into reservoirs and lakes, resulting in water quality problems with sometimes expensive solutions (Yoon and Raymond 2012; 
Mukundan et al. 2013; Mukundan and Van Dreason 2014; Sinha et al. 2017). Extreme streamflow events have been shown to increase turbidity in the Ashokan reservoir, putting more strain on the Delaware and Croton subsystems as withdrawals from them are increased (Rossi et al. 2016). Fortunately, in comparison to most water supply systems, this one is relatively resistant to the worst impacts due to its capacity, physical size, and variety of inter-basin transfer options, so that appropriate management practices can minimize the worst impact of extreme events (Porter et al. 2015). However, in the wake of large, region-wide events such as Irene and Lee, no system can simultaneously minimize all the potential impacts on water quality, quantity, downstream recreational uses, and ecological integrity.

\section{Data}

In our study, we examine variations as far back in time as possible using precipitation and streamflow gage observations within and surrounding the Catskill Mountains. Figure 1 shows the locations of precipitation (circles) and stream (squares) gages considered for (open symbols) and included in (filled symbols) this analysis. The criteria for inclusion are discussed in detail below.

Daily precipitation observations are obtained from Global Historical Climate Network (GHCN) daily data set (https://www.ncdc.noaa.gov/data-access/landbased-station-data/land-based-datasets/global-historical-climatology-networkghcn; Menne et al. 2012). The availability of stations from this network changes considerably over time, with many stations dropping out since the late 1990s. As a result, the sets of stations included in recent studies of this region (Matonse et al. 2013; Acharya et al. 2017) differ from each other and would have to differ from any study that required data from more recent years. To address this issue, the first analysis presented in this paper demonstrates this problem and describes how we identify a viable set of stations to define the historical precipitation climatology of this region. Table S1 lists the precipitation stations considered for inclusion in our analysis.

Historical daily average streamflow records are obtained from the U.S. Geological Survey (USGS) surface water website (https://waterdata.usgs.gov/nwis/sw). Most of the land in these basins is protected, resulting in no significant land use change during the period of record. No diversions, reservoir operations, or other human flow alterations occur above these gages, so that gage variations primarily reflect climatological changes rather than management decisions (Matonse and Frei 2013). Basin areas range from $65 \mathrm{~km}^{2}$ to $850 \mathrm{~km}^{2}$. Table S2 lists the stations used in this study. Prior to analysis, mean daily streamflow volumetric units are 
converted to centimeters of depth by dividing by basin area to facilitate direct comparison to precipitation observations.

The National Hurricane Center produces a dataset of tracks for tropical storms (HURDAT2; Landsea and Franklin 2013). We use this dataset to link events identified by the gage observations in our study with tropical storms. Any storm that passes through a box around our region approximately $500 \mathrm{~km}$ wide within one day of an event is associated with that event and labeled accordingly in the figures. HURDAT2 stops tracking storms shortly after they start losing their tropical structure, so it cannot provide information on all storms of tropical origin, but only on storms that have retained their tropical characteristics near the time of impact in our region. For example, HURDAT2 storm tracks data for Lee stops in the southern US when it underwent extratropical transition and acquired extratropical characteristics.

\section{Methods}

The set of statistical techniques employed here is chosen so as to minimize the number of statistical assumptions as much as possible and to be resilient to the non-Gaussian statistical distribution of daily data. Furthermore, analyses are performed separately for warm (June through November) and cold (December through May) seasons based on previous studies that demonstrate the seasonal dependencies of climatological extreme statistics and trends in extremes (Matonse and Frei 2013; Frei et al. 2015). The methodologies and results include two main parts: the precipitation gage station processing methodology and the statistical methodology for evaluating Irene and Lee in the context of other extreme events in our region. Each is discussed separately below.

\subsection{Precipitation gage data processing}

The goal of this endeavor is to identify a set of station records appropriate for evaluating climatological variations in precipitation in our region extending as far back in time as possible and including variations during recent years as well. The data processing proceeds in three steps: identification of stations to be considered for inclusion; evaluation of records to select stations with record lengths and completeness that meet our criteria for inclusion in further analysis; and identification of pairs of stations that can be combined to result in more complete records. Each step is described below.

\subsubsection{Identification of precipitation stations to be considered for inclusion}

To identify precipitation stations that could potentially contribute to a long-term analysis, all stations within watershed counties (i.e., counties in which lie at least a 
part of one of our study basins) with metadata indicating data availability between 1960 and 2012 were chosen (see justification in Section 4.1.2 below). In addition, other stations in neighboring counties that have long, fairly continuous records are included. Finally, any stations that were included in previous reports (Matonse and Frei 2013; Acharya et al. 2017) but did not meet either of the first two criteria are also chosen. The resulting stations are shown in Figure 1.

\subsubsection{Evaluation of record length and completeness}

As meteorological records in general, especially those based on volunteer reporting as many of these are, have records of variable length and completeness, the decision on criteria for inclusion is at least partially subjective. Based on previous experience using the station data and knowledge of the local climate, it was clear that a number of records began between the late 1940s and late 1950s and that the frequency of extreme events dropped after 2012. Thus, the criteria for inclusion in subsequent analyses are that station records must have at least 80 percent non-missing data during at least 80 percent of the years between 1960 and 2012. The evaluation was also performed with more strict (90 percent) and less strict (70 percent) criteria, but the subjective decision to choose 80 percent was made as a compromise between the number of stations and record completeness.

\subsubsection{Precipitation station combination}

The goal of this step is to lengthen station records that were chosen for inclusion, or to combine stations that individually fail to meet the criteria for inclusion but together can meet the criteria. Stations are considered for combination if their combination would provide a longer record. Stations are combined if they meet the following conditions: (1) they have the same location name (different stations located in the same town) and are located less than $5 \mathrm{~km}$ from each other or (2) they are located less than $10 \mathrm{~km}$ from each other (whether they have the same location name or not); and they have overlapping records and meet the quantile regression (QR) criteria discussed subsequently. When records are combined, one is considered "primary," which means on days when both stations have values, the primary stations value is retained. Combined stations are then considered as one record.

Scatter plots of daily precipitation values from nearby stations reveal that heteroscedasticity (i.e., the variance of the dependent variable around the mean regression line is not constant with the independent variable) is significant in these stations, rendering the inferential statistics produced by ordinary least square (OLS) regression unreliable. Instead of OLS, we employ QR (Koenker and Basset Jr. 1978). In contrast to OLR, which estimates the mean of the response variable as 
a function of the predictor variable, QR estimates quantiles (i.e., percentiles, such as the median) of the response variable as a function of the predictor variable. QR is a non-parametric technique that is more appropriate than OLS for our purposes in two ways: it allows one to avoid the assumption of homoscedasticity and provides the ability to estimate confidence limits as a function of the predictor variable, in contrast to OLS which, based on the assumption of homoscedasticity, estimates constant confidence limits.

This technique has been used in climatological analyses (e.g., Jagger and Elsner 2008; Wasko and Ashish 2014; Fan and Chen 2016), but, to our knowledge, not for this specific purpose.

As readers may not be familiar with QR, we demonstrate its efficacy for our purpose. Figure 2 shows two pairs of synthetic data sets ( $X$ and $Y, n=100$ ). The data in the top panel meet all the assumptions of OLS. The data in the bottom
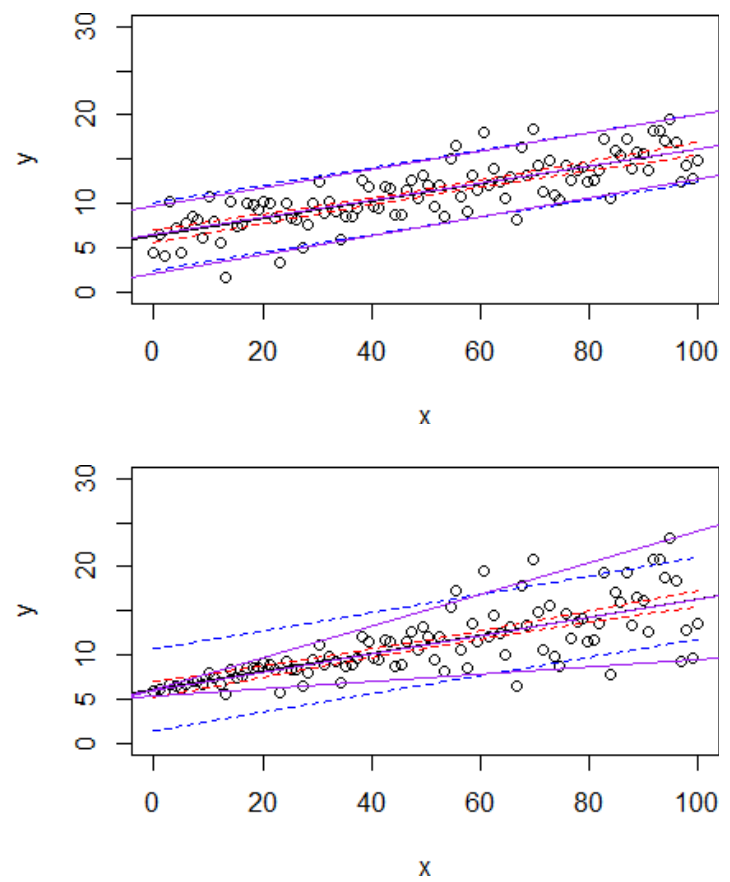

Figure 2. (Color online) Comparison of OLS Regression and QR on Synthetic Data $(n=100)$ Notes: The data in the top panel meet OLS assumptions. The data in the bottom panel are heteroscedastic. OLS results (dashed lines) show the mean regression line, 90 percent confidence interval for the mean regression line (red dashed), and 90 percent confidence interval for individual data points (blue dashed). QR results (solid lines, purple) show the median regression line, as well as the 5th quantile and 95th QR lines (which together are comparable to OLS 90 percent confidence interval). See text for discussion. 
panel are heteroscedastic because the variance of $Y$ increases with $X$. In both cases, the OLS mean regression lines and the QR median regression lines are identical. In the homoscedastic case (top panel), the 90 percent confidence intervals for data points based on OLS are indistinguishable from those based on QR. In the heteroscedastic case (bottom panel), OLS confidence intervals are overestimated for smaller $X$ values and underestimated for larger $X$ values, whereas QR confidence intervals realistically increase with $X$. Daily precipitation scatter plots from nearby stations in our region resemble the heteroscedastic case. Thus, when considering whether the observations from two nearby stations can be merged into a single record, we rely on QR rather than on OLS, using the criteria that the 5 percent quantile line must have a slope significantly greater than zero with $p<0.05$. There is no quantitative justification for this criterion, except to say that it is conservative (only four station combinations meet the criterion); and it maintains a median slope of 1 between the two stations. QR analyses were performed using the quantreg package (Koenker 2016) of the R software package (R Core Team 2014).

\subsection{Identification of events}

In our region, more than 95 percent of events have $\leq 5$ days of consecutive precipitation, and the maximum number of consecutive precipitation days at any station is 25 days. In this analysis, we identify precipitation and streamflow events using the method of Frei et al. (2015), which is briefly summarized here, and analyze results for events of length 1 day, 5 days, 30 days, and 60 days. Events are by definition non-overlapping (i.e., each day can be included in only one event). One-day events are analyzed using the daily observations.

For $n>1$ we define an " $n$-day" event using a two-step decision process. First, any series of consecutive $\leq n$ days with daily precipitation greater than zero bounded by dry days is considered an $n$-day event. In step 2 , we must also consider $n$-day events that occur within longer strings of consecutive precipitation days. This is accomplished by choosing the $n$-day event with the largest total precipitation within the longer string of precipitation days. All remaining days are then considered in a similar fashion. For example, if we are analyzing 5-day events, and come across a series of seven consecutive precipitation days, the five consecutive days with the largest total precipitation are identified as an event, and the remaining two days are either two 1-day events or one 2-day event. This method captures all potential large precipitation events of any length.

As there are no naturally defined consecutive $n$-day precipitation events of length 60 days in our region, events of these lengths are simply defined by choosing the non-overlapping consecutive days of length $n$ with the largest total precipitation. As the streams considered in this analysis generally have baseflow 
even during the dry season, and therefore do not have events bounded by "dry" days, streamflow "events" are identified using the same method as we use for longer precipitation events. These might more correctly be called $n$-day totals rather than events.

Precipitation and streamflow events are defined independently of each other and independently at each station. This leaves several options for ranking events. For example, events can be ranked by the largest station value or the mean station value. To ensure that the events identified are regional in scale, events are ranked by median station value. This means that after events are identified using the method described earlier, each event is associated with a streamflow (or precipitation) magnitude at each station. The median value among all the stations is then saved, and all the events on record can then be ranked according to the median station value of each event. There are events in these records that are more localized, which can be identified by ranking events by the maximum station value, but those are not the subject of this analysis.

\subsection{Analysis of events}

To evaluate Irene and Lee in the context of historical events, we employ two different types of bar graphs. In the first, magnitudes of the 25 largest precipitation and 25 largest streamflow events (for a total of 50 events) in our time domain are shown on bar graphs. In the second, tallies of the number of stations recording a top 3 event during each month are shown on bar graphs. Both are explained more fully in Section 5.

\section{Results}

\subsection{Precipitation gage data processing}

\subsubsection{Identification of stations to be considered for inclusion}

Record completeness varies through time and between stations, such that at some stations the 80 percent criterion is not achieved in any year, whereas at other stations the criterion is met frequently (see Figure S1). For example, station 57 (located on the slope of Slide Mountain, the highest peak in this region) has a fairly complete record from 1949 through 2011; station 19 (from Cooperstown in the northern part of our study region) has a fairly complete record from around 1930 through 2016, with additional data in the late 19th century. Of the nine stations from the Binghamton group, station 7 (located at the airport) has a fairly complete record from the early 1950s through 2016, whereas station 8 has a fairly complete record from the 1920s through the early 1970s. If these two Binghamton stations 


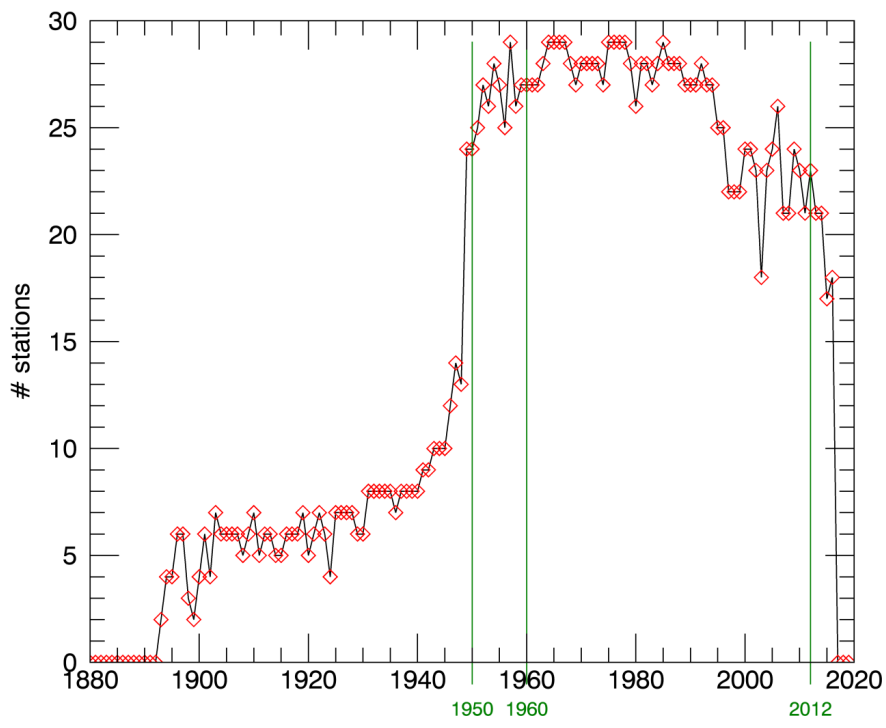

Figure 3. (Color online) Data Availability Summary

Notes: Number of stations per year with 80 percent non-missing data per year. $X$-axis shows year with 1950, 1960, and 2012 emphasized. $Y$-axis shows number of stations. Stations refer to the original stations prior to any combination of station records.

can be combined, the result will be one station with a record length longer than either one individually (unfortunately, as discussed subsequently, they do not meet the criteria for combining).

Figure 3 summarizes the variation in data availability through time. Five to seven stations have records from the 1890s through around 1940, with the number of available stations rising during the 1940s, particularly after 1948, and peaking at 29 for any particular year. The number of stations drops to between 20 and 25 during the early-to-mid 1990s.

\subsubsection{Precipitation station combination}

First, in order to produce longer records, stations are combined if they meet any of the criteria discussed in the methodology section. Seventeen potential combinations were considered. In some cases, this could mean extending a record that already meets our criteria. In other cases, it could mean combining records that individually do not meet our criteria, but in combination have potential to meet the criteria. Table S1 includes information on which stations were combined.

Examples of the QR analyses are shown in Figure 4. Each panel shows precipitation data for days when the records overlap. The two panels in the top row show the only two pairs of stations from the same location name at which the QR 
criteria were met (Delhi and Rock Hill); the two panels in the middle row show the only two "nearby" (defined in Section 5.1) stations at which the QR criteria were met (Unadilla-Bainbridge and Slide-Phonecia); the two panels in the bottom row are examples of QR results that do not meet the criteria. (The two Binghamton stations discussed earlier do not meet the criteria.)

Figure 5 shows the availability through time of 19 precipitation stations which meet our criteria and are available for inclusion in subsequent analyses. Of those,
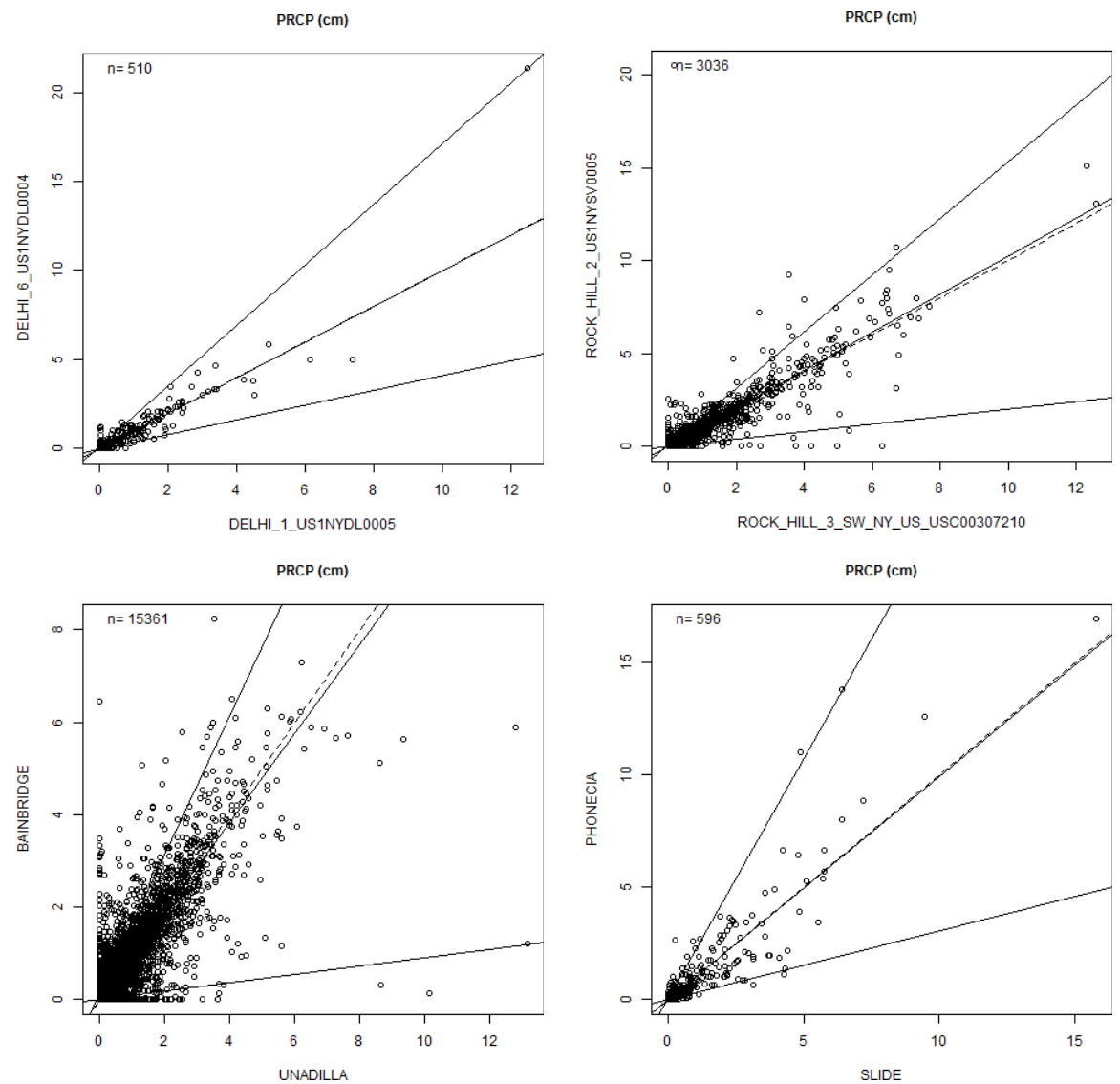

Figure 4. Examples of QR Comparisons of Daily Precipitation

Notes: Each panel includes a dashed line showing slope $=1$, and three solid lines showing the 95th, 50th, and 5th quantile lines, and indicates $n$, the number of overlapping data points included in the analysis. Within-group stations from Delhi and Rock Hill (top row) and nearby stations UnadillaBainbridge and Slide-Phonecia (middle row) meet the criteria for combination because the slope of the bottom (5th quantile) line is significantly greater than zero; in those cases, the median regression line has a slope close to one. All other comparisons do not meet the criteria: examples of withingroup failed comparisons (Binghamton and Unadilla) are shown (bottom row). 

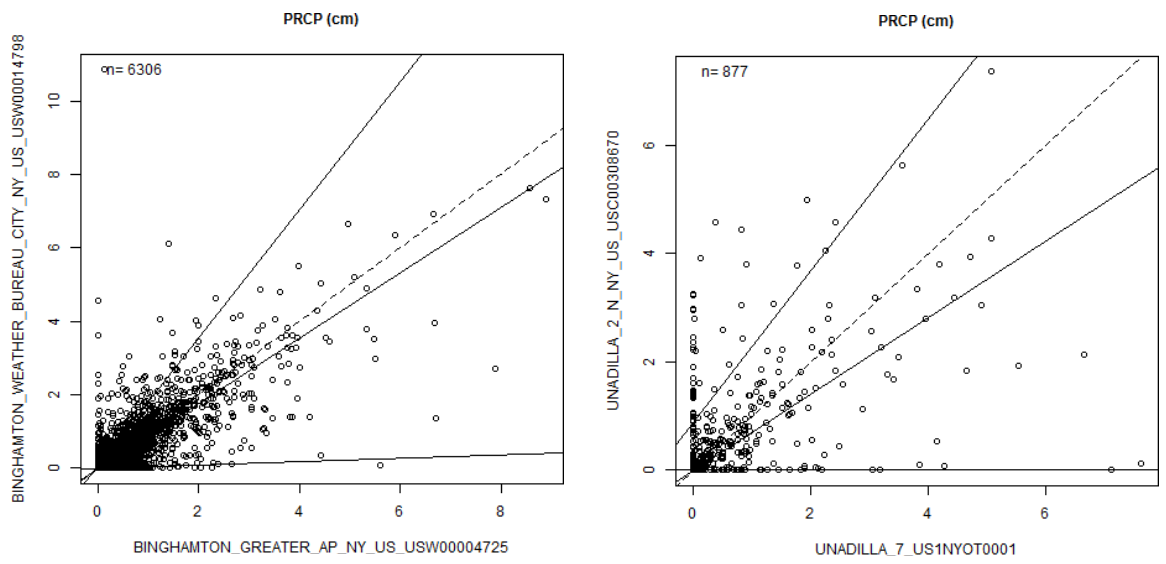

Figure 4. (Continued)

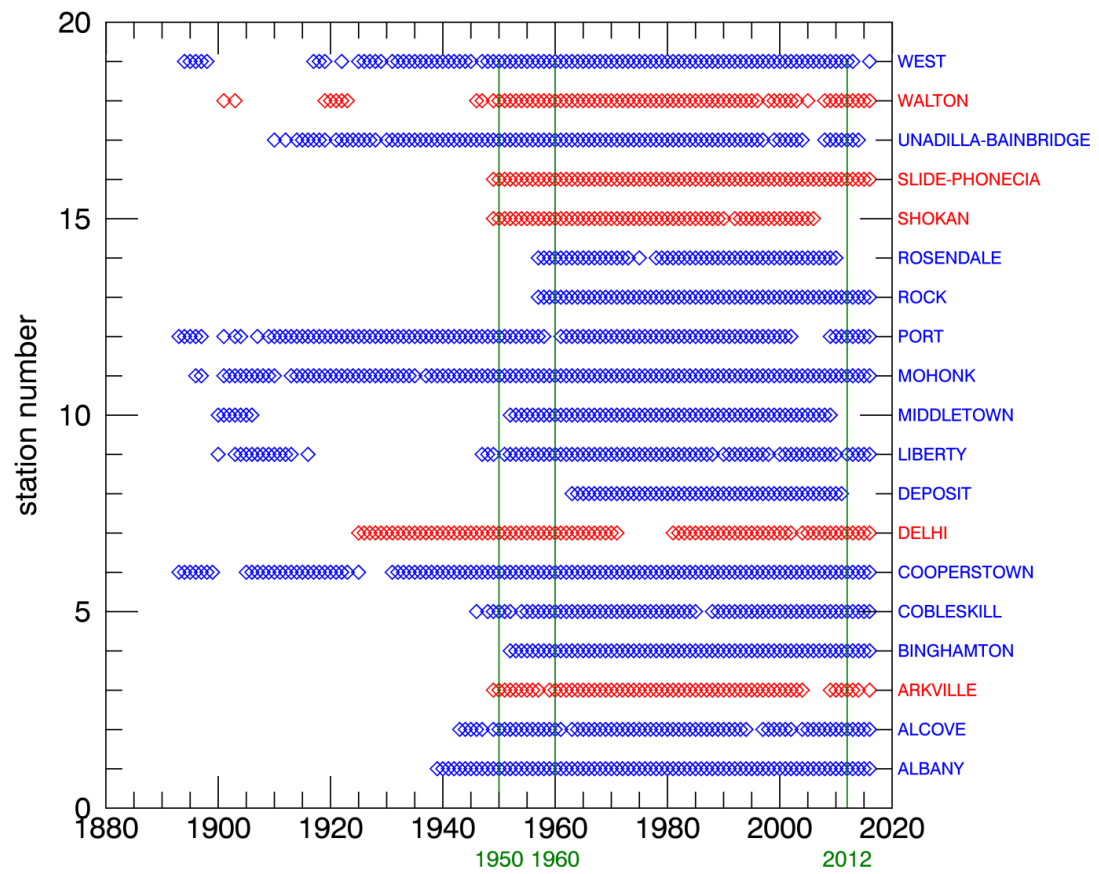

Figure 5. (Color online) Data Availability for Each of the 19 Stations that Meet the 0.8 Criteria for Inclusion

Notes: For each station, symbols indicate years with at least 80 percent non-missing daily precipitation data. $X$-axis shows year, with 1950, 1960, and 2012 emphasized. $Y$-axis (right) shows station name. The five stations shown in red are located within the watershed. 


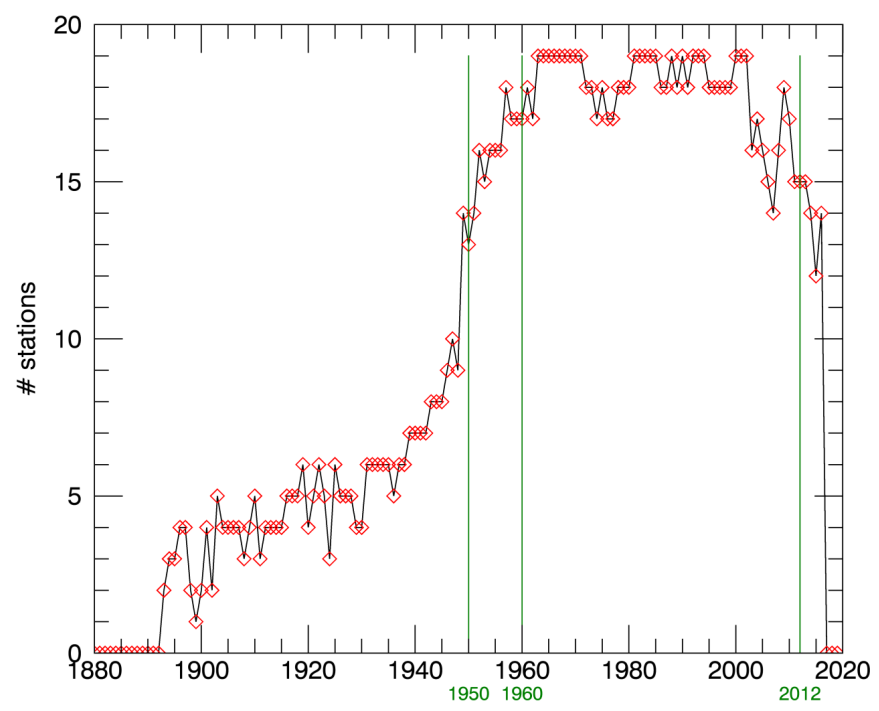

Figure 6. (Color online) Summary of Station Analysis

Notes: Similar to Figure 3 except including only the 19 records that meet the 0.8 criteria. These records include all combined stations that met our criteria.

only five (colored red in the figure) are located within the watershed. Six records are reasonably continuous back to the 1920s, only one of which is located within the watershed boundaries. Station names are shown on Figure 5, and their locations are shown on Figure 1.

Temporal changes in the availability of data that meet the 80 percent criteria (Figure 6) reflect variations in total data availability (Figure 3). Only one to six stations per year meet the criteria between the 1890s and 1940. Station records become more available between 1940 and 1960, rising to between 17 and 19 stations per year; the numbers remain steady until $\sim 2000$, at which time the station count starts dropping.

Of course, station selection and the station count depend strongly on our subjective criteria. With less strict criteria at 70 percent, 25 stations, including 13 within the watershed boundaries, would be selected. With more strict criteria set at 90 percent, only 12 stations, including three in the watershed, would be selected. For other applications, a different set of criteria may be chosen, but all results discussed further in this report are based on stations selected using a criteria value of 80 percent.

\subsection{One-day event magnitudes, 1950-2016}

The top panel of Figure 7 shows the largest 1-day annual or "ANN" events (including data from all months of the year). In this and subsequent figures, the bar 

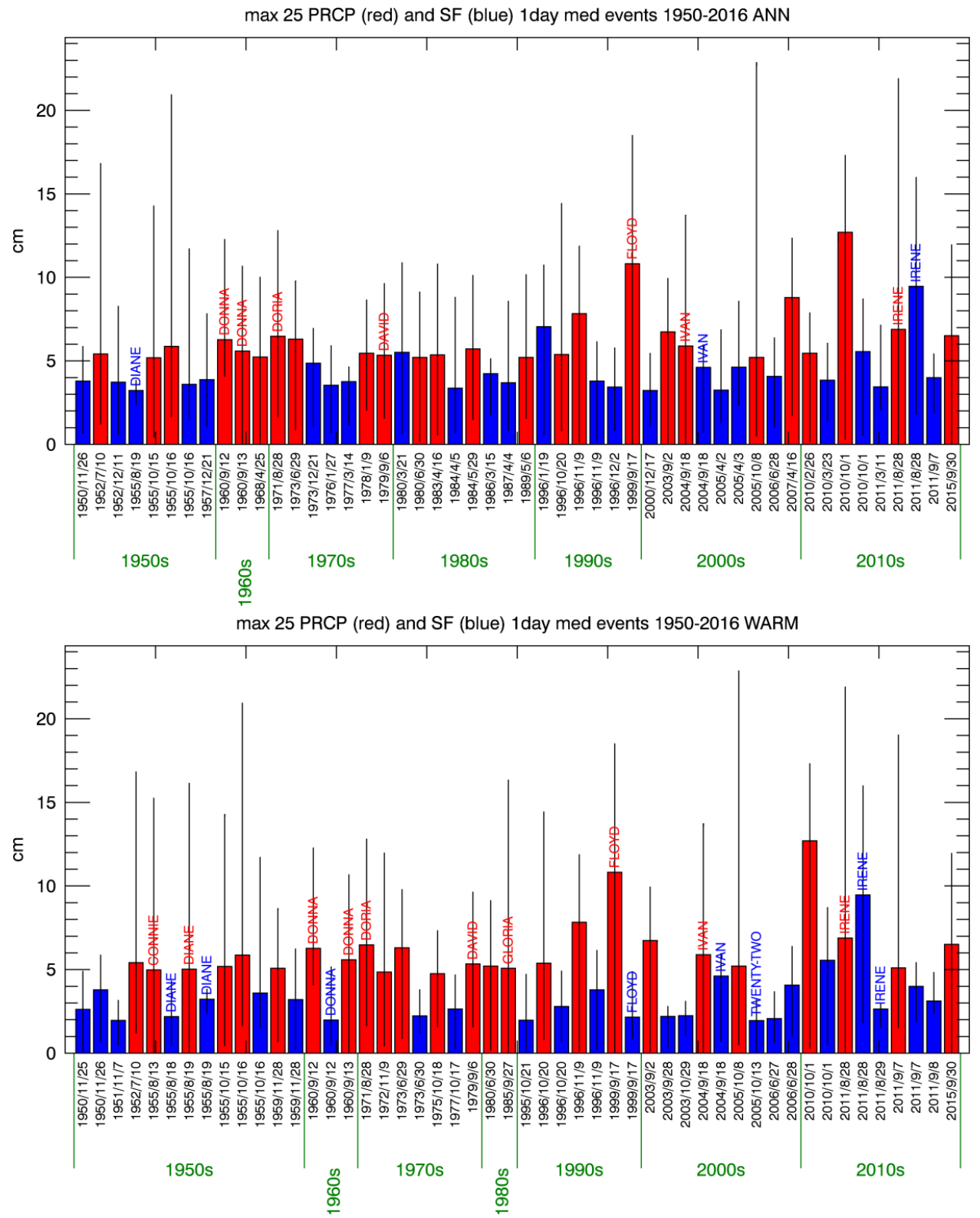

Figure 7. (Color online) Magnitudes of the Top 25 1-Day Precipitation (Red) and Streamflow (Blue) Events, 1950-2016, Ranked by Median Station Values

Notes: Top panel includes all events; bottom panel includes warm season (June-November) only. Bars show median value from all stations; black whiskers show range of values from all stations. $X$-axis shows dates of events; green lines emphasize decades. Events corresponding to named tropical storms as they appear in the HURDAT2 data set are labeled. Events dated 7 and 8 September 2011 correspond to Lee. 
height indicates the median station value, whereas the whiskers indicate the range of station values. In this figure, 18 of the top 25 precipitation events occur during the warm season. In contrast, 16 of the top 25 streamflow events occur during the cold season. Events are summarized in Table S3.

Irene is associated with the fifth largest 1-day precipitation event, but with the single largest streamflow event on record. Although precipitation events tend to be larger than their associated streamflow responses, only for Irene is the streamflow response larger than the precipitation event. This can occur because the streams were already running high when Irene hit, and the "response" refers to the total streamflow during and after the event. The second largest streamflow event is associated with the snowmelt flood of January 1996 ( $\sim 7 \mathrm{~cm}$ compared with Irene's $\sim 9.5 \mathrm{~cm}$ ). The magnitude of the next highest streamflow event, October 2010, is less than 60 percent of that of Irene. Irene was a very large precipitation event, but using the 1-day streamflow metric Irene towers over other events.

Lee appears on this graph as the streamflow event on September 7, 2011, which is ranked 10th highest on record. As a precipitation event, it was ranked 28 and therefore does not appear in this panel. Other precipitation events of note include: October 2010 (rank 1), Hurricane Floyd in September 1999 (rank 2), April 16, 2007 (rank 3), and November 9, 1996 (rank 4). The streamflow event ranked third behind Irene and January 1996 occurred in October 2010.

Below the $x$-axis of this figure is included a decadal timeline to visually indicate the decade during which events occurred. Of the 50 events ( 25 precipitation and 25 streamflow) appearing in this figure, 23 occurred between 1996 and 2011. This is more than would be expected if events occurred randomly in time and more than any other comparable time period on record.

Figure 7 (bottom panel) shows the 25 maximum daily precipitation (red) and streamflow (blue) events including only the warm season. Similar to the annual results discussed earlier, 23 of the top 50 events between 1950 and 2016 occur between 1996 and 2011. More events occur in September (9) and October (6) than any other months.

Irene produced the fourth largest and Lee the 19th largest, 1-day warm season precipitation events. Each of them resulted in two days with streamflow magnitudes among the top 25 since 1950: Irene had the largest and 13th ranked, and Lee had the 5th and 11th ranked, 1-day streamflow events. Other events that produced two top 25 1-day streamflow events include: the storm of June 26-28, 2006 (which does not appear in the top 25 1-day precipitation list) and Hurricane Diane in August 1955. Note that in addition to the 1996-2011 period, the 1950s were also extreme, whereas the 1960s and 1980s were relatively calm. Thus, when considered according to the metric of 1-day events, Irene and Lee are unprecedented, but other events are close. 


\subsection{Five-day event magnitudes, 1950-2016}

The seasonal differences between extreme precipitation and streamflow events are even more obvious when considered in the context of 5-day, rather than 1-day, events (Figure 8, top panel). (Reminder: 5-day events include all events of length $\leq 5$.)
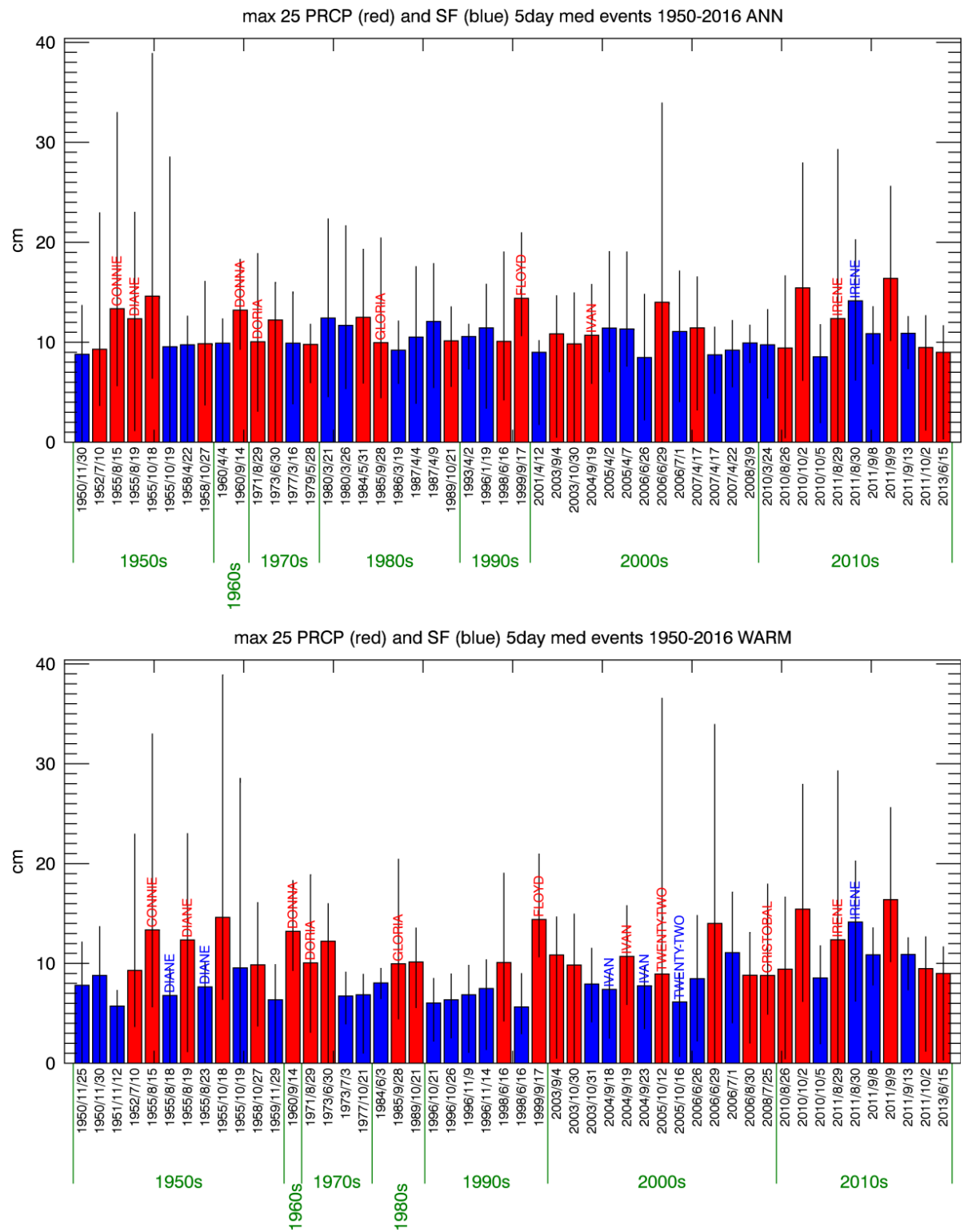

Figure 8. (Color online) Same as Figure 7 but for 5-Day Events 
Extreme 5-day precipitation events occur overwhelmingly (22 of the largest 25) during the warm season, primarily between August and October, when the tropical influence is strongest. In contrast, 17 of the top 25 5-day streamflow events occur during the cold season, associated with snow melt. In contrast, the drought of the 1960s affects extreme event records all year round, with only one precipitation event (Hurricane Donna in September 1960) and one streamflow event (a snow ablation event in April 1960) from that decade appearing in the top 25 chart. Events are summarized in Table S4.

Furthermore, the unique characteristics of the recent period, and in particular of fall 2011, become more striking when considered in the context of 5-day events. Twenty-six of the 50 events since 1950 occurred between 1996 and 2011, including six during the calendar year 2011 alone. The series of events during fall 2011 is unique for several reasons (Figure 8, top panel). Lee emerges as the largest precipitation event on record. Irene is the only tropical storm appearing in the top 25 streamflow rankings (although others such as Lee are of tropical origin). In fact, three 5-day precipitation events during the fall of 2011 (Irene ranked 9th on August 28-29, Lee on September 5-9, and a 5-day event ending on October 2 ranked 22nd) appear among the 25 largest. Even more remarkably, during one 15-day period in fall 2011, three consecutive 5-day streamflow events (one associated with Irene and two with Lee, ranked 1, 10, and 9) appear on the top 25 list.

No other comparable series of events can be found in this record. The only four instances in which two top 25 5-day streamflow events occurred consecutively were all March or April events associated with snow ablation (March 1980; April 1987; April 2005; and April 2007), only one of which was also associated with a top-25 precipitation event.

When considering only warm season events (Figure 8, bottom panel), the extreme events of the recent period and of the 1950s emerge in stark contrast to the intervening decades. Twenty-nine of the 50 extreme 5-day warm season hydrological events occurred between 1996 and 2011; 12 such events occurred during the 1950s; leaving only nine events during the entire period 1960-1995.

The fall 2011 season stands out using the 5-day warm season metric. Three of the top 25 extreme precipitation events on record occurred during the 2011 fall season: Lee (September 5-9, ranked 1st); Irene (August 25-29, ranked 8th); and the storm ending October 2 (ranked 19th). The streamflow statistics are even more impressive. Three of the top four events were due to Irene (August 26-30, ranked 1st) and Lee (September 9-13, ranked 3rd; September 4-8, ranked 4th). 
The 1955 warm season is also remarkable in this record. Hurricanes Connie and Diane in August 1955 were the 6th and 9th ranked precipitation events and were followed by the 13th and 18th ranked streamflow events. These were exceeded a few months later by the storm of October 1955, which ranked 3rd for precipitation and 5th for streamflow.

\subsection{Antecedent conditions, $1950-2016$}

Several events of note in the 5-day warm season results (Figure 8, bottom panel) demonstrate the importance of antecedent conditions in influencing the magnitudes of streamflow responses to storms. In some cases, storms result in streamflow responses disproportionally large compared with the precipitation magnitude. In November 1950, for example, the region experienced two top 25 streamflow events (ranked 6th and 11th) but the precipitation event ranked below 200 (according to the median station value, although in one basin the storm was more extreme). In fall 1996, four 5-day streamflow events appear in the top 25 (ranked between 14 and 23), associated with four much less severe precipitation events (ranked between 30 and 88). Hurricane Ivan in September, 2004 ranked 12th in precipitation and elicited two consecutive extreme 5-day streamflow events ranked 12th and 15th.

Other times the streamflow response to a storm is disproportionally mild. Hurricane Floyd in September, 1999, while an infamous flooding event across other parts of the east coast, in our region ranked ahead of Ivan (4th) on the 5-day warm season precipitation scale but, with a rank of 27, did not make the top 25 on the streamflow scale.

Hurricanes Connie and Diane in August, 1955 demonstrate both ends of the streamflow response spectrum. Connie, which arrived at the tail end of a dry period, lasted five days and ranked 6th in total precipitation but resulted in no significant streamflow response. Connie was followed less than a week later by Diane, whose total precipitation was similar to Connie's but which lasted only two days. Diane, dropping its moisture on a more saturated surface thanks to Connie, elicited two consecutive top 25 5-day streamflow events ranked 13th and 18th. Farther downstream in the Delaware River Basin the flooding was catastrophic (Schafer 2015).

\subsection{Tallies of top 3 events by date, 1950-2016}

To further compare and contrast different hydrological periods in the Catskills, we turn to the second mode of analysis. Although the full complement of seasons and event lengths were analyzed, the main points are most concisely illustrated by restricting the discussion to warm season 5-day and 60-day tallies. The column charts in Figure 9 have stacked columns for each month during which any 
precipitation or streamflow station recorded a top 3 5-day event (top panel) or 60-day event (bottom panel). Red bars represent precipitation and blue bars represent streamflow. The height of the column indicates the number of top 3 events during that month. Each column is stacked with up to three different shades, associated with, from dark to light, ranks of 1 , 2, and 3, respectively.

The tallest blue column in the top panel of Figure 9 shows that 11 top 3 streamflow events occurred during September 2011. Of these, three were ranked 1st, five ranked 2nd, and three ranked 3rd. During only two other months on record did more than one stream gage record a top 3 event (i.e., had a count greater than 1). During October 1955, a total of six top 3 events occurred, of which five were ranked 1st and one was ranked 2nd. In June 2006, six events were recorded, with one ranked 1st. Clearly, September 2011 is unique, although October 1955 had more top-ranked events.

With regard to 5-day precipitation events (Figure 9, top panel), while fall 2011 appears to be among the most extreme periods, several other periods are equally or more extreme. For example, in October 2005, six top-ranked events were recorded, in contrast to only one top-ranked event in 2011. October 2010 and October 1955 also appear to have been similarly extreme on this chart. Thus, while fall 2011 appears to be unique with regard to 5-day streamflow events, with regard to 5-day precipitation events, other periods seem to have been comparably or even more extreme.

An explanation for this apparent discrepancy is suggested by the 60-day total precipitation and streamflow tallies (Figure 9, bottom panel). The number of top 3 60-day precipitation events during fall 2011 far exceeds any other period. Twelve stations had top-ranked, and another four stations had 2nd or 3rd ranked, 60-day precipitation events ending in fall 2011. The next most active precipitation period was summer (June, July, and August) 2006, when three stations experienced topranked, seven stations 2nd-ranked, and four stations 3rd-ranked events. The other two periods whose 60-day precipitation totals appear unusually extreme are fall 1977 and fall 1955.

With regard to streamflow, nine stations recorded a top 3 event in fall 2011, including seven ranked first and two ranked second. Only one other period, fall 1977, is found when any stream gage experienced its largest event on record. Thus, one can infer that the 5-day storms of fall 2011 elicited much larger streamflow responses than previous storms of comparable magnitudes because they occurred within a much rainier period and presumably fell on more saturated soils.

In fact, this relationship seems to be consistent throughout these records. The regionally widespread extreme 5-day precipitation events of August 1955, October 1955, September 1999, October 2005, June 2006, October 2010, and September 2011 
did not all elicit widespread extreme streamflow responses. In every case, when the 60-day precipitation total was extreme, the 5-day streamflow response to a storm was also extreme (October 1955, June 2006, and September 2011); when the 60-day total precipitation is not extreme, neither was the 5-day streamflow response (August 1955, September 1999, October 2005, October 2010).

\subsection{Tallies of top 3 events by date, 1900-2016}

The results described so far include data back to only the 1950s. However, six precipitation gage records extend back to the 1920s or farther. Although five of these stations are located outside of the watershed, since we are focusing on regional scale events, it seems reasonable to assume that the same extreme events would be present in the five long-term stations; to be sure, we corroborate that assumption (below). Furthermore, most of the stream gage records extend back to the 1930s. Thus, to see whether the events of fall 2011 were unique when considering events back to the early 20th century, we performed two sets of analyses using data back to 1900 from the six long-term precipitation stations and data back to the beginning of records (i.e., 1930s) for the same set of stream gages as in the previous analyses.

First, we perform the same analysis as discussed earlier, extending back to 1950, but using only the long-term precipitation stations. The results of this analysis (not shown), including both 5-day and 60-day warm season events, are consistent with the results discussed earlier, indicating that these stations can be used to extend the analysis farther back in time.

Secondly, we perform the same analysis using the long-term precipitation stations (and the same streamflow stations) extending back to 1900 (Figure 10). With regard to 5-day events (Figures 10 and 11, top panel), the stream gage records indicate extraordinary events in September 2011, June 2006, and October 1955. The long-term precipitation records (Figure 10, top panel) indicate that, consistent with the other set of stations shown in Figure 9 (top panel), October 2005 was the most extreme event on record; that the 1940s had few events; and that the 1930s were relatively active. In addition, an event in October 1903 emerges in these results. In fact, of the top 25 5-day precipitation events between 1900 and 2016, four occurred in the 1900s and five occurred in the 1930s, with only three events between the 1910s and 1920s (not shown). These results confirm that the 5-day events of fall 2011 were unique with regard to streamflow but not to precipitation; and that in addition to the recent period, the 1900s, 1930s, 1950s, and 1970s appear to have been relatively active.

The long-term results show starkly that the 60-day events of fall 2011 were unique back to the turn of the twentieth century (Figure 10, bottom panel). 
\# sta with top 3 PRCP (red) and SF (blue) 5day totals 1900-2016 WARM

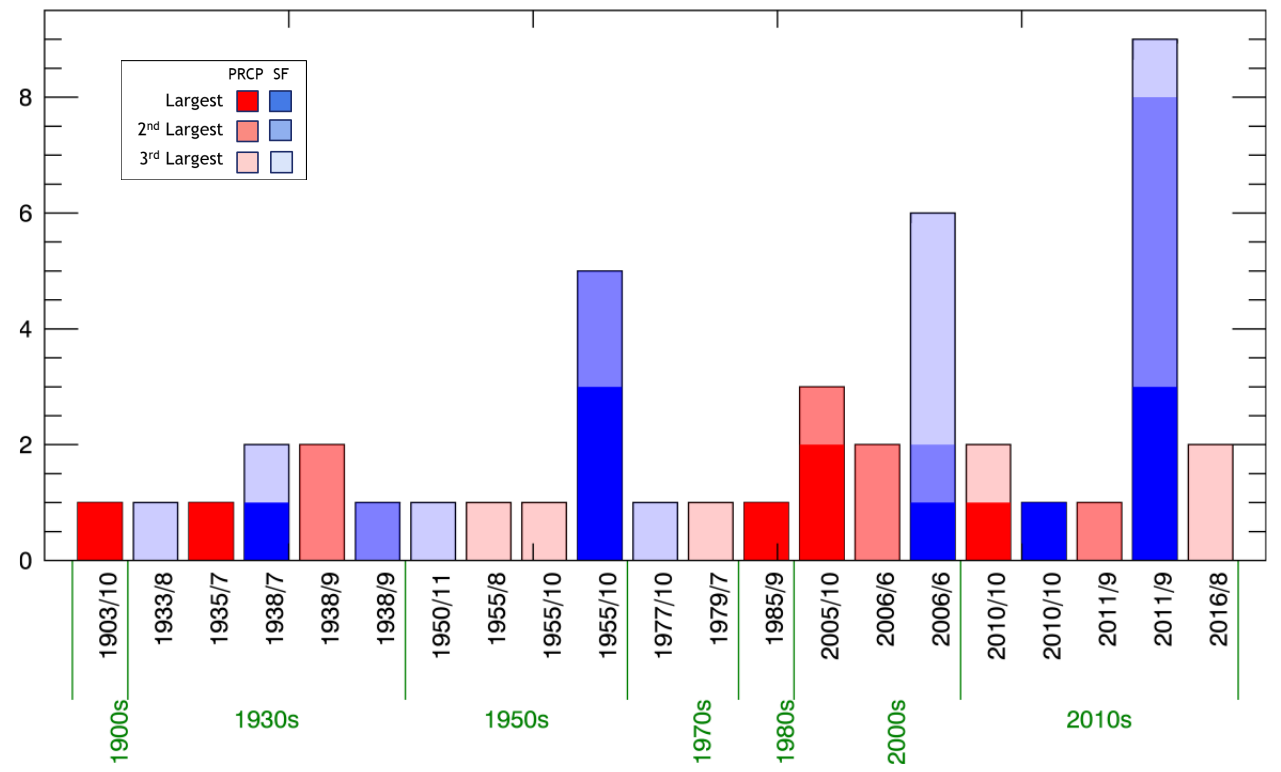

\# sta with top 3 PRCP (red) and SF (blue) 60day totals 1900-2016 WARM

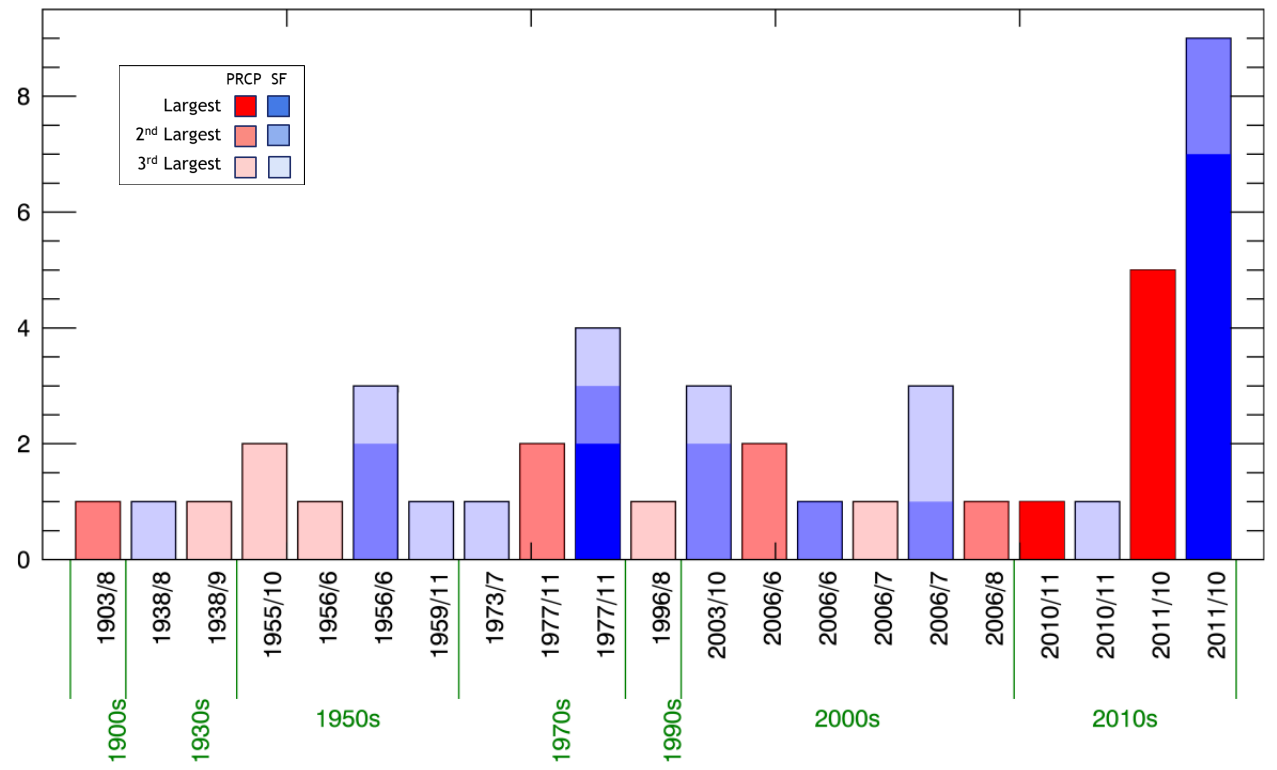

Figure 10. (Color online) Same as Figure 9 but for 1900-2016, Including Long-term Precipitation Stations Only 
The stream gage records extended back to the 1930s do not change the previous results (compare Figures 10 and 9, bottom panels). The six long-term precipitation stations had the same set of extreme events, including (in addition to fall 2011) November 2010; June 2006; November 1977; and October 1955. In addition, events in September 1938 and August 1903 also emerge on this chart. The 60-day results confirm again that the 1900s, 1930s, 1950s, 1970s, and the recent period were relatively wet.

\section{Discussion and Conclusions}

It is clear from these results that the period from 1996 through 2011 as well as the fall season of 2011 are both unique in the context of the last 100 or so years, thus corroborating the perceptions of local residents. This is consistent with other reports that the perception of hydrological extremes on such time scales is closely related to the gaged record (Goebbert et al. 2012). These results also suggest the possibility of a roughly 20-year cycle in the frequency of extreme events in this region. We find evidence of wet periods and extreme events in the 1900s, 1930s, 1950s, 1970s, and the recent period. A great deal of research exists describing and explaining drought cycles of similar periodicities in the central and western US (Currie 1984; Cook et al. 1997, 2014; Woodhouse and Overpeck 1998; Gray et al. 2003; Devineni et al. 2013; Abatan et al. 2017), but to our knowledge limited literature (Shulte et al. 2015) exists for the northeast. These Catskill cycles seem to be out of phase with the central/western cycles where significant droughts occurred in the 1930s and 1950s. Such a phase difference may be related to atmospheric wave patterns. Shulte et al. (2015) link 18- and 26-year cycles in our region to atmospheric circulation patterns.

Precipitation and streamflow gage records do not extend much farther back than the turn of the twentieth century, so in order to quantitatively evaluate events much farther back in time, an alternative source of data is required. Fortunately, proxy records in the form of tree rings from the Catskills have been analyzed and can help put our results in the context of a longer time frame. Although tree ring reconstructions do not specifically reflect either the frequencies or magnitudes of extreme events at subseasonal time scales, they do accurately reflect seasonal scale variations in the hydrological state of the environment. Tree ring studies from this region indicate that, while droughts comparable to the 1960s have previously occurred in this region, the recent pluvial was unprecedented in duration and magnitude (Pederson et al. 2012; Devineni et al. 2013). As the results presented here suggest that seasonal scale precipitation is an indicator of the requisite antecedent conditions for extreme streamflow responses to storms, we infer that the 
frequency and magnitude of extreme floods between 1996 and 2011 are probably unmatched in the last 500 years.

Although some of the details of the results presented here, such as the exact magnitudes and rankings of events, are functions of the available station distribution and therefore could change if the methodology or station selection was slightly altered, a number of general conclusions can be confidently drawn based on this analysis, including the following.

(1) A strong seasonal signature in the climatology of extreme hydrological events is found in this region. Historically, extreme streamflow events occur preferentially during the cold season and are associated with snow ablation, whereas extreme precipitation events occur preferentially during the warm season (primarily August through October) and are often associated with storms of tropical origin. The seasonal signature is starker when considering events of five days rather than one day. This seasonal difference in extreme event magnitudes is not the same as a seasonal difference is extreme event trends (not shown here), which during the last few decades have been increasing more during the warm season in the Catskills (Matonse and Frei 2013) as well as across the northeastern US (Frei et al. 2015) for both precipitation and streamflow. The drought of the 1960s was associated with a diminished frequency of extreme hydrological events during both seasons.

(2) The period from 1996 through 2011 was the most active since the early 20th century, and probably for the last 500 years, for extreme warm season hydrological events. Twenty-nine of the top 50 5-day warm season hydrological events since 1950 occurred during this recent period. The 1950s were also a very active period: 12 of the top 505 -day warm season events occurred during that decade. Only 9 of the top 50 5-day warm season events occurred during the period 1960 through 1996; however, the 1970s were wet with regard to 60-day events. More limited observations from the period 19001950 are consistent with these conclusions and suggest that the 1900s, 1930s, 1950s, 1970s, and recent period were relatively wet. Tree ring studies suggest that the recent pluvial is unmatched in the last half millennium.

(3) Antecedent moisture conditions, as indicated in this study by 60-day precipitation totals, play an important role in determining the magnitude of the streamflow responses to extreme warm season precipitation events. For example, of seven extreme 5-day warm season precipitation events analyzed (defined as events during which several stations recorded a top 3 precipitation event), only the three cases that occurred during a wet season (i.e., a season with a top 3 60-day precipitation event) elicited a top 3 5-day streamflow response. 
(4) Irene and Lee, or more generally the events of fall 2011, were indeed unique in the Catskill Mountain region for the last $\sim 100$ years and probably the last 500 years. While the 5-day precipitation events were very large, the 5-day streamflow responses were unprecedented. The large streamflow responses to storms during this time were related to the unusually wet antecedent conditions, associated with the largest 60-day precipitation as well as streamflow values on record. As a result, during the fall 2011 season, three 5-day precipitation events ranked among the top 25 warm season events on record (ranked 1st, 9th, and 22nd), while three of the four largest 5-day warm season streamflow events occurred during this season (ranked first, second, and fourth). The 1996-2011 pluvial identified in the gage record appears to be unmatched in the last 500 or so years according to local tree ring records.

\section{Acknowledgments}

We acknowledge the financial support of the New York City Department of Environmental Protection under their Climate Change Integrated Modeling Program; research assistants from the Hunter College Department of Geography and the CUNY Institute for Sustainable Cities, including Miri Dainson, Glenn Liu, Nunny Reyes, Anastasia Tom, and Paradorn Wongchanapai; and two anonymous reviewers whose suggestions helped streamline and clarify the paper.

\section{References}

Abatan, AA, Gutowski WJ Jr, Ammann CM, Kaatz L, Brown BG, Buja L, Bullock R, Fowler T, Gilleland E and Gotway JH (2017). Multiyear droughts and pluvials over the Upper Colorado River Basin and associated circulations. Journal of Hydrometeorology, 18(3): 799-818, doi: 10.1175/jhm-d-16-0125.1.

Acharya, N, Frei A, Chen J, DeCristofaro L and Owens E (2017). Evaluating stochastic weather generators for climate change impact studies of New York City's primary water supply. Journal of Hydrometeorology, 18: 879-896, doi: 10.1175/JHM-D-16-0169.1.

Anandhi, A, Pradhanang S, Zion M, Pierson D, Frei A and Schneiderman E (2011). AR4 Climate Model performance in simulating snow water equivalent over Catskill Mountain watersheds, New York, USA. Hydrological Processes, 25: 3302-3311, doi: 10.1002/hyp.8230.

Brandon, C, Garman N and Ryan M (2012). Good Night Irene: Stories and Photos About the Tropical Storm that Devastated Vermont, the Catskills, and the Berkshires. Keene, NH: Surry Cottage Books, ISBN: 978-0-9829853-2-8.

Burns, DA, Klaus J and McHale MR (2007). Recent climate trends and implications for water resources in the Catskill Mountain region, New York, USA. Journal of Hydrology, 336: 155-170, doi: 10.1016/j.jhydrol.2006.12.019. 
Cook, ER, Meko DM and Stockton CW (1997). A new assessment of possible solar and lunar forcing of the bidecadal drought Rhythm in the Western United States. Journal of Climate, 10(6): 1343-1356, doi: 10.1175/1520-0442(1997)010<1343:anaops>2.0.co;2.

Cook, BI, Smerdon JE, Seager R and Cook ER (2014). Pan-continental droughts in North America over the last millennium. Journal of Climate, 27(1): 383-397, doi: 10.1175/ jcli-d-13-00100.1.

Currie, RG (1984). Periodic (18.6-year) and cyclic (11-year) induced drought and flood in western North America. Journal of Geophysical Research: Atmospheres, 89(D5): 7215-7230, doi: 10.1029/JD089iD05p07215.

DeGaetano, AT and Castellano CM (2013). Recent and future changes in extreme rainfall in the Catskills region of New York. Annals of the New York Academy of Sciences, 1298(1): 43-51, doi: 10.1111/nyas.12245.

Devineni, N, Lall U, Pederson N and Cook E (2013). A tree-ring-based reconstruction of Delaware River Basin streamflow using hierarchical Bayesian regression. Journal of Climate, 26(12): 4357-4374, doi: 10.1175/jcli-d-11-00675.1.

Fan, L and Chen D (2016). Trends in extreme precipitation indices across China detected using quantile regression. Atmospheric Science Letters, 17(7): 400-406, doi: 10.1002/ asl.671.

Fang, X and Pomeroy JW (2016). Impact of antecedent conditions on simulations of a flood in a mountain headwater basin. Hydrological Processes, 30: 2754-2772, doi: 10.1002/hyp.10910.

Frei, A, Armstrong RL, Clark MP and Serreze MC (2002). Catskill Mountain water resources: Vulnerability, hydroclimatology, and climate change sensitivity. Annals of the Association of American Geographers, 92(2): 203-224, doi: 10.1111/1467-8306.00287.

Frei, A, Kunkel KE and Matonse A (2015). The seasonal nature of extreme hydrological events in the Northeastern United States. Journal of Hydrometeorology, 16(5): 20652085, doi: 10.1175/JHM-D-14-0237.1.

Galusha, D (1999). Liquid Assets: A History of New York City's Water System. Purple Mountain Press. ISBN: 978-1930098329.

Gazoorian, CL (2012). How extreme was Irene? A comparison of the 2011, 1996, 1987 floods along the Schoharie Creek. Proceedings of the 2012 Mohawk Watershed Symposium, Union College, Schenectady, NY, pp. 17-22.

Goebbert, K, Jenkins-Smith HC, Klockow K, Nowlin MC and Silva CL (2012). Weather, climate, and worldviews: The sources and consequences of public perceptions of changes in local weather patterns. Weather, Climate, and Society, 4(2): 132-144, doi: 10.1175/wcas-d-11-00044.1.

Gray, ST, Betancourt JL, Fastie CL and Jackson ST (2003). Patterns and sources of multidecadal oscillations in drought-sensitive tree-ring records from the central and southern Rocky Mountains. Geophysical Research Letters, 30(6), doi: 10.1029/2002GL016154.

Hanlon, JW (2017). Complementary safeguards for robust regional watershed governance in a federation: New York City and its municipal water supply. Environmental Science and Policy, 75: 47-55, doi: 10.1016/j.envsci.2017.04.014.

Hanlon, J, Olivier T and Schlager E (2017). Institutional adaptation and effectiveness over 18 years of the New York City watershed governance arrangement. Environmental Practice, 19(1): 38-49, doi: 10.1080/14660466.2017.1275709. 
Ivancic, TJ and Shaw SB (2015). Examining why trends in very heavy precipition should not be mistaken for trends in very high river discharge, Climatic Change, 133(4), 681-693, doi: 10.1007/s10584-015-1476-1.

Jagger, TH and JB Elsner (2008). Modeling tropical cyclong intensity with quantile regression. International Jounral of Climatology, 29(10): 1351-1361, doi: 10.1002/ joc.1804.

Koenker, R and Gilbert Bassett J (1978). Regression quantiles. Econometrica, 46(1): 33-50, doi: $10.2307 / 1913643$.

Koenker, R (2016). Quantreg: Quantile Regression. R package version 5.21.

Kunkel, KE, Karl TR, Brooks H, Kossin J, Lawrimore J, Arndt D, Bosart L, Changnon D, Cutter SL, Doesken N, Emanuel K, Groisman PY, Katz RW, Knutson T, O’Brien J, Paciorek CJ, Peterson T, Redmond K, Robinson D, Trapp J, Vose R, Weaver S, Wehner M, Wolter K and Wuebbles D (2013). Monitoring and understanding trends in extreme storms. American Meteorological Society, 94(4): 499-514, doi: 10.1175/ BAMS-D-11-00262.1.

Landsea, CW and Franklin JL (2013). Atlantic Hurricane database uncertainty and presentation of a new database format. Monthly Weather Review, 141: 3576-3592, doi: 10.1175/MWR-D-12-00254.1.

Lumia, R, Firda GD and Smith TL (2014). Floods of 2011 in New York: U.S. Geological Survey Scientific Investigations Report 2014-5058, 236.

Matonse, A and Frei A (2013). A seasonal shift in the frequency of extreme hydrological events in southern New York State. Journal of Climate, 26(23): 9577-9593, doi: 10.1175/jcli-d-12-00810.1.

Matonse, A, Pierson DC, Frei A, Zion MS, Anandhi A, Schneiderman E and Wright B (2013). Investigating the impact of climate change on New York City's primary water supply. Climatic Change, 116(3): 437-456, doi: 10.1007/s10584-012-0515-4.

Melillo, JM, Richmond TC and Yohe GW (2014). Climate change impacts in the United States: The Third National Climate Assessment, U.S. Global Change Research Program.

Menne, MJ, Durre I, Vose RS, Gleason BE and Houston TG (2012). An overview of the Global Historical Climatology Network-Daily Database. Journal of Atmospheric and Oceanic Technology, 29: 897-910, doi: 10.1175/JTECH-D-11-00103.1.

Miller, S, Kidd G, Montalto F, Gurian P, Worrall C and Lewis R (2014). Contrasting perspectives regarding climate risks and adaptation strategies in the New York metropolitan area after superstorm Sandy. Journal of Extreme Events, 1(1): 1450005, doi: 10.1142/S2345737614500055.

Mukundan, R, Pierson DC, Schneiderman EM, O’Donnell DM, Pradhanang SM, Zion MS and Matonse AH (2013). Factors affecting storm event turbidity in a New York City water supply stream. Catena, 107: 80-88, doi: 10.1016/j.catena.2013.02.002.

Mukundan, R and Dreason RV (2014). Predicting trihalomethanes in the New York City Water Supply. Journal of Environmental Quality, 43: 611-616, doi: 10.2134/ jeq2013.07.0305.

Pederson, N, Bell AR, Cook ER, Lall U, Devineni N, Seager R, Eggleston K and Vranes $\mathrm{KJ}$ (2012). Is an epic pluvial masking the water insecurity of the Greater New York City Region? Journal of Climate, 26: 1339-1354, doi: 10.1175/JCLI-D-11-00723.1. 
Peterson, TC, Heim JRJ, Hirsch R, Kaiser DP, Brooks H, Diffenbaugh NS, Dole RM, Giovannettone JP, Guiguis K, Karl TR, Katz RW, Kunkel KE, Lettenmaier D, McCabe GJ, Paciorek CJ, Ryberg K, Schubert S, Silva VBS, Stewart BC, Vecchia AV, Villarini G, Vose RS, Walsh J, Wolock D, Wolter K, Woodhouse CA, Wehner M and Wuebbles D (2013). Monitoring and understanding changes in heat waves, cold waves, floods and droughts in the United States: State of knowledge. Bulletin of the American Meteorological Society, 94: 821-834, doi: 10.1175/BAMS-D-12-00066.1.

Porter, JH, Matonse AH and Frei A (2015). The New York City Operations Support Tool (OST): Managing water for millions of people in an era of changing climate and extreme hydrological events. Journal of Extreme Events, 2(2): 1550008, doi: 10.1142/s2345737615500086.

Pradhanang, SM, Anandhi A, Mukundan R, Zion MS, Pierson DC, Schneiderman EM, Matonse A and Frei A (2011). Application of SWAT model to assess snowpack development and streamflow in the Cannonsville watershed, New York, USA. Hydrological Processes, 25(21), doi: 10.1002/hyp.8171.

Ralston, DK, Warner JC, Geyer WR and Wall GR (2013). Sediment transport due to extreme events: The Hudson River estuary after tropical storms Irene and Lee. Geophysical Research Letters, 40(20): 5451-5455, doi: 10.1002/2013GL057906.

R Core Team (2014). R: A language and environment for statistical computing. V. R Foundation for Statistical Computing, Austria.

Rossi, N, DeCristofaro L, Steinschneider S, Brown C and Palmer R (2016). Potential impacts of changes in climate on turbidity in New York City's Ashokan Reservoir. Journal of Water Resources Planning Management, 142(3): 04015066, doi: 10.1061/ (ASCE)WR.1943-5452.0000614.

Schafer, M (2015). Devastation on the Delaware: Stories and Images of the Deadly Flood of 1955, 3rd Edition. Riegelsville PA, USA: World Forge Books, ISBN: 097713296X.

Sinha, E, Michalak AM and Balaji V (2017). Eutrophication will increase during the 21st century as a result of precipitation changes. Science, 357(6349): 405-408, doi: 10.1126/science.aan2409.

Solecki, W, Frei A, Sofranko S, Gruber S, Matonse A, Patrick L, Leichenko R and Brady M (2014). Hydrology, vulnerability and adaptation implications of Hurricane Irene and Tropical Storm Lee: Case study of the Mid-Hudson Valley and Greater Catskills Regions, New York State Energy Research and Development Authority. Report Number 14-40.

Solecki, W and Rosenzweig C (2014). Climate change, extreme events, and Hurricane Sandy: From non-stationary climate to non-stationary policy. Journal of Extreme Events, 1(1): 1450008, doi: 10.1142/S2345737614500080.

Soll, D (2013). Empire of Water: An Environmental and Political History of the New York City Water Supply. Cornell University Press. ISBN: 978-0-8014-4990-1.

Stradling, D (2007). Making Mountains: New York City and the Catskills. University of Washington Press. ISBN: 978-0295990149.

Teale, NG, Quiring SM and Ford TW (2017). Association of synoptic-scale atmospheric patterns with flash flooding in watersheds of the New York City water supply system. International Journal of Climatology, 37(1): 358-370, doi: 10.1002/joc.4709.

Thaler, JS (1996). Catskill Weather. Purple Mountain Press. ISBN: 978-0935796797. 
Towey, KL, Booth JF, Frei A and Sinclair MR (2017). Track and circulation analysis of tropical and extratropical cyclones that cause extreme precipitation and streamflow events in the New York City Watershed. Journal of Hydrometeorology. In review.

Wasko, C and Ashish S (2014). Quantile regression for investigating scaling of extreme precipitation with temperature. Water Resources Research, 50(4): 3608-3614, doi: 10.1002/2013WR015194.

Woodhouse, CA and Overpeck JT (1998). 2000 years of drought variability in the Central United States. Bulletin of the American Meteorological Society, 79(12), doi: 10.1175/ 1520-0477(1998)079<2693:yodvit>2.0.co;2.

Yoon, B and Raymond PA (2012). Dissolved organic matter export from a forested watershed during Hurricane Irene. Geophysical Research Letters, 39: L18402, doi: 10.1029/2012GL052785.

Zion, MS, Pradhanang SM, Pierson DC, Anandhi A, Lounsbury DG, Matonse AH and Schneiderman EM (2011). Investigation and modeling of winter streamflow timing and magnitude under changing climate conditions for the Catskill Mountain region, New York, USA. Hydrological Processes, 25(21): 3289-3301, doi: 10.1002/hyp.8174. 